\title{
Improved Sound Absorption Performance of Nonwoven Fabric using Fabric Facing and Air Back Cavity
}

\author{
Ahmad Yusuf Ismail ${ }^{1, *}$, Muhamad Rafi Omar ${ }^{1}$, Muhamad Arif Anuar Hashim ${ }^{1}$, and \\ Muhamad Ridzuan Md Radzi ${ }^{1}$ \\ ${ }^{1}$ ViBRO Research Group, Centre for Advanced Research on Energy (CARe) \\ Faculty of Engineering Technology, Universiti Teknikal Malaysia Melaka, Durian Tunggal, 76100, \\ Melaka, Malaysia
}

\begin{abstract}
This paper presents the improvement methods to increase sound absorption performance of polyethylene based nonwoven fabric (PNF). The methods are placing a woven fabric in front of the sample as well as providing air cavity behind the sample. The samples were experimentally tested in an impedance tube based on ISO 10354-2:2001 whereby two microphones are used and the transfer matrix methods are employed. From the results, it can be seen that placing front woven fabric effectively increases sound absorption performance. Moreover, introducing air cavity gap behind the sample is also found to be more significant to increase sound absorption.
\end{abstract}

\section{Introduction}

The nonwoven industry has changed and grown rapidly since its beginning decades ago. The growth is including expansion with many other technologies and applications in textile industry [1]. In automotive industry, particularly, nonwoven fabric has been widely applied for interior cabin materials [2 - 3]. This is due to the good acoustical performances of the nonwoven fabric which provides good insulation from noise sources.

Researchers have been investigated the nonwoven fabric particularly for sound insulation applications. Lee and Joo (2003) investigate the sound absorption performance of recycled polyester nonwoven fibrous materials. It is found that the absorption can be significantly changed by controlling the fibre and web properties [4]. Parikh et.al. (2006) fabricate nonwoven fabric from natural waste fibres for automotive floor applications. Kenaf, jute, waste cotton as well as flax are mixed with polypropylene and polyester. It is found that their sound insulation performance is good and relatively better than commercial cotton pad [5]. Tascan and Vaughn (2006) study the effect of total surface area and fabric density of a needle punch nonwoven fabric on the acoustical performance. It is found that both parameters are proportional with the sound insulation obtained [6]. Kucuk and

*Corresponding author: ahmadyusuf.ismail@utem.edu.my 
Korkmaz (2012) also study the effect of physical parameters i.e. thickness, weight per unit area, air permeability on the sound absorption performance. By increasing the thickness and reducing the air permeability, sound absorption performance is significantly increased [7]. Liu et.al. (2014) use general regression neural network for predicting sound absorption of sandwich nonwoven fabric. Parametric study is also conducted in the research. It is found that the prediction is reliable and efficient to be used [8]. Tiuc et.al. (2016) creatively improve sound insulation performance of polyurethane (PU) foam by mixing the PU with nonwoven textile waste. The result shows that by certain composition of the nonwoven waste fabric and PU foam, the sound insulation can be improved [9]. Shimizu and Koizumi (2015) conduct a compatibility study of a nonwoven fabric that is installed as gap and slits cover. Although it is thin, but the result shows that the nonwoven cover provides good sound insulation without distracting flow resistivity [10]. Recently, Ghorbani et.al. (2015) investigate the sound insulation performance of polypropylene needle punch nonwoven fabric. It is found that the most influential factor to increase insulation is the web mass. By increasing the mass, the sound insulation performance is improved significantly [11].

From previous researches, one can note that most of the factor that gives significant effect to increase sound insulation is the physical parameters. This paper, therefore, investigates the effect of another physical parameter i.e. air back cavity as well as additional front woven fabric cover purposely to improve the sound absorption performance of nonwoven fabric.

\section{Materials and method}

\subsection{Material preparation}

In this research, polyethylene based nonwoven fabric (PNF) as seen in Fig. 1 was chosen and used as a sample due to its wide application in industry [2 - 3]. The thickness of the sample was set to be 1,2 and $3 \mathrm{~cm}$. While the air cavity gap behind the sample was set to be $0.5,1$ and $1.5 \mathrm{~cm}$. A commercial woven fabric was used to cover the PNF in the experiment.

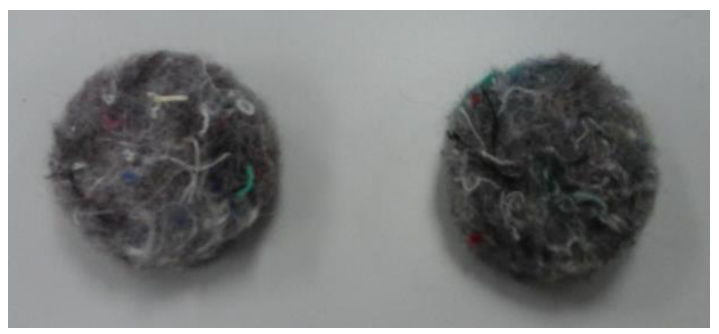

Fig. 1. Nonwoven fabric (PNF).

\subsection{Experimental setup}

The measurement setup is shown in Fig. 2. This uses the impedance tube method according to ISO 10534-2:2001 [12]. The sample was placed against rigid backing and the loudspeaker at the other tube end. Two acoustic microphones, The G.R.A.S $1 / 2$ inch freefield type 40AE were located in the front of the sample to save the incident and reflected acoustic signals. ACUPRO software and spectrum analyser was used as the data acquisition system. 
The diameter of the tube was $29.4 \mathrm{~mm}$ and the tube was capable to provide frequency range between $100-5000 \mathrm{~Hz}$. This corresponds to the diameter of the tube as well as the reliability of the software. The recorded signal was processed in the ACUPRO software and all the result was presented in one-third octave band frequency.

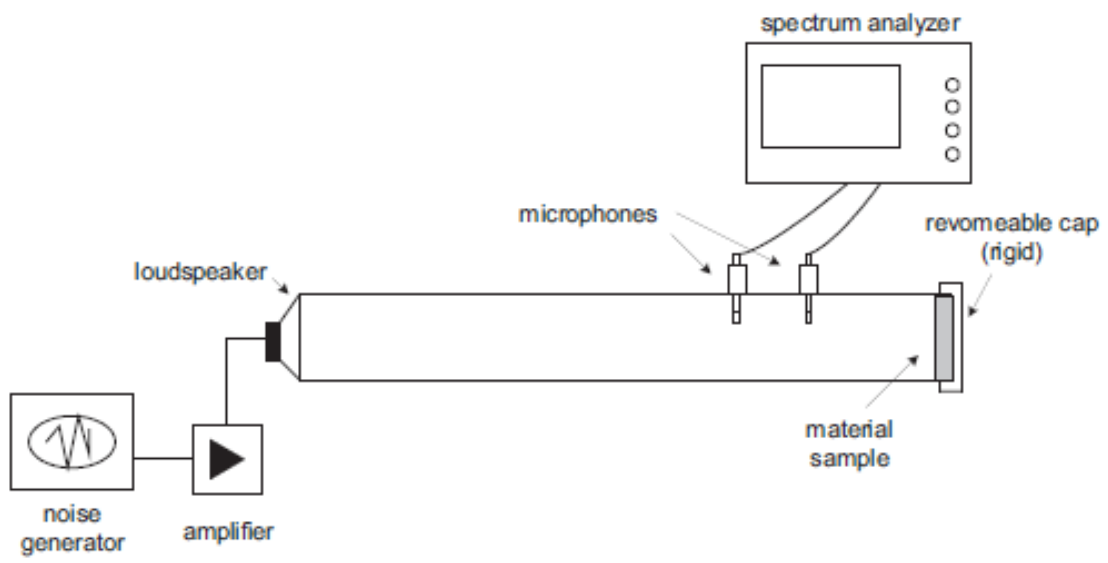

Fig. 2. Experimental Setup.

\section{Results and discussion}

Fig. 3 shows the initial observation of sound absorption performance from PNF. It is seen that the thickness of the fibre plays a major role in increasing absorption. As the thickness increases, the sound absorption performance is increased as well. This is similar with previous research results $[7,11]$ whereby the sample thickness increasing the porosity and mass density. This, in turn, makes more absorption of sound energy.

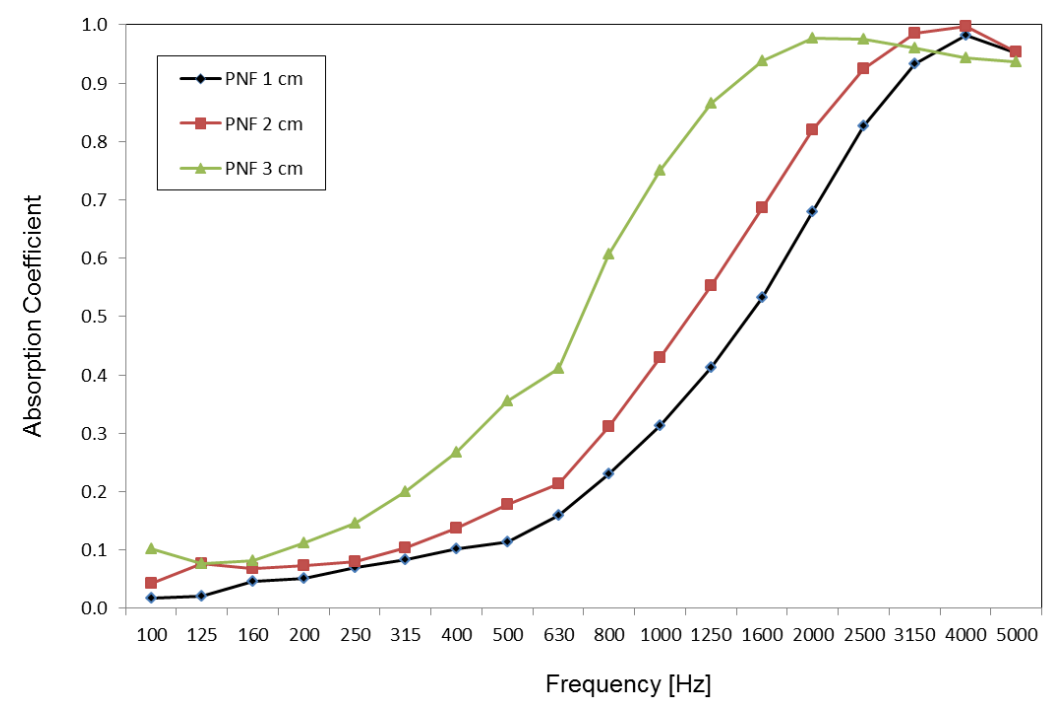

Fig. 3. Sound absorption of PNF in several thicknesses.

While Fig. 4 and 5 shows the effect of placing front woven fabric on the sound absorption performance. It can be seen that even thin woven fabric facing (FF) may 
increase the absorption performance. From 250 to $2000 \mathrm{~Hz}$ the increment is obtained roughly by 0.05 . At around $500-650 \mathrm{~Hz}$, the increment achieves its peak for almost reaching 1 increment. This is interesting since the use of front woven fabric often far from discussion. The even fibre matrix from the front woven facing effectively dissipates most of incident sound energy into the PNF where eventually lean the absorption processes in the nonwoven porosity. This dissipation is still effective even if the thickness of the PNF is increased as seen in Fig. 5.

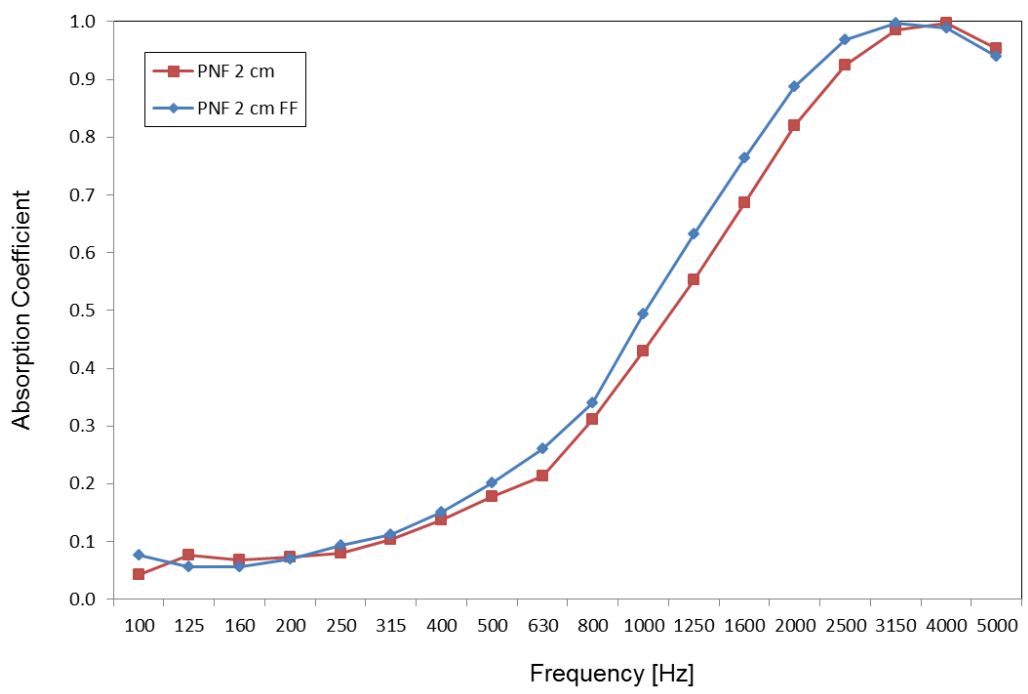

Fig. 4. The effect of front woven fabric facing (FF) on the sound absorption.

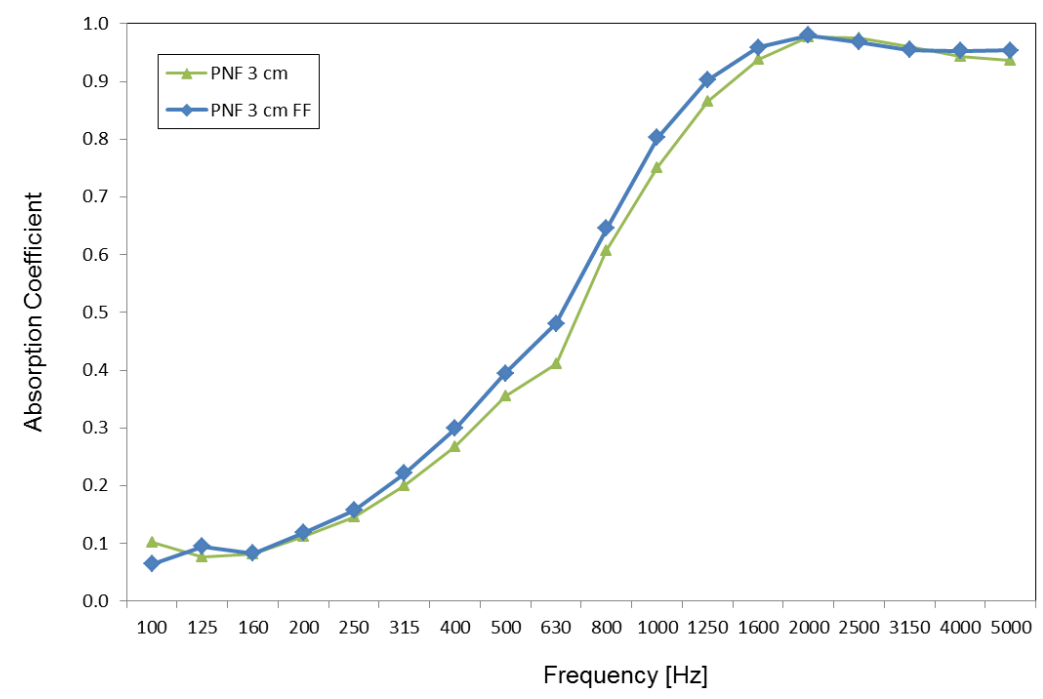

Fig. 5. The effect of front woven fabric facing (FF) on the sound absorption.

Fig. 6 shows the effect of air back cavity on the sound absorption. It is clearly seen that adding air back cavity increases the sound absorption significantly. The bigger the gap, the higher absorption obtained. The increment is obtained almost for all frequency range. It can also be said that the increment of air cavity gap shifts the absorption performance to the 
lower frequency range. From the figure as well, it is also seen that the peak absorption performance is shifted to the lower frequency while the cavity gap is increased. This is very useful when the noise source is dominant at low frequency region.

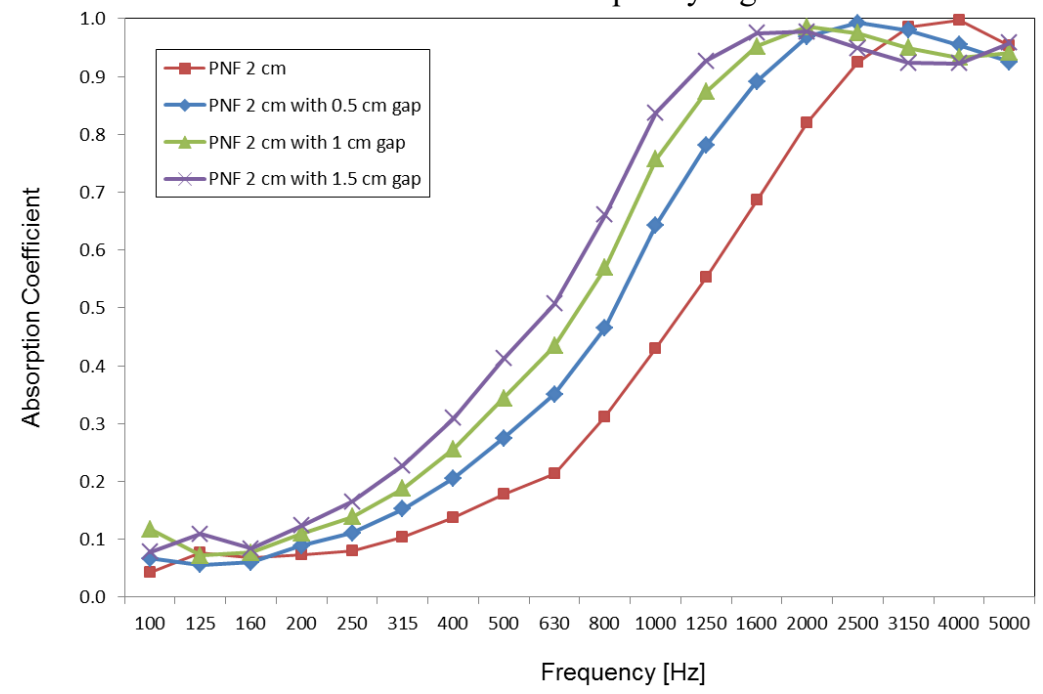

Fig. 6. The effect of air back cavity on the sound absorption.

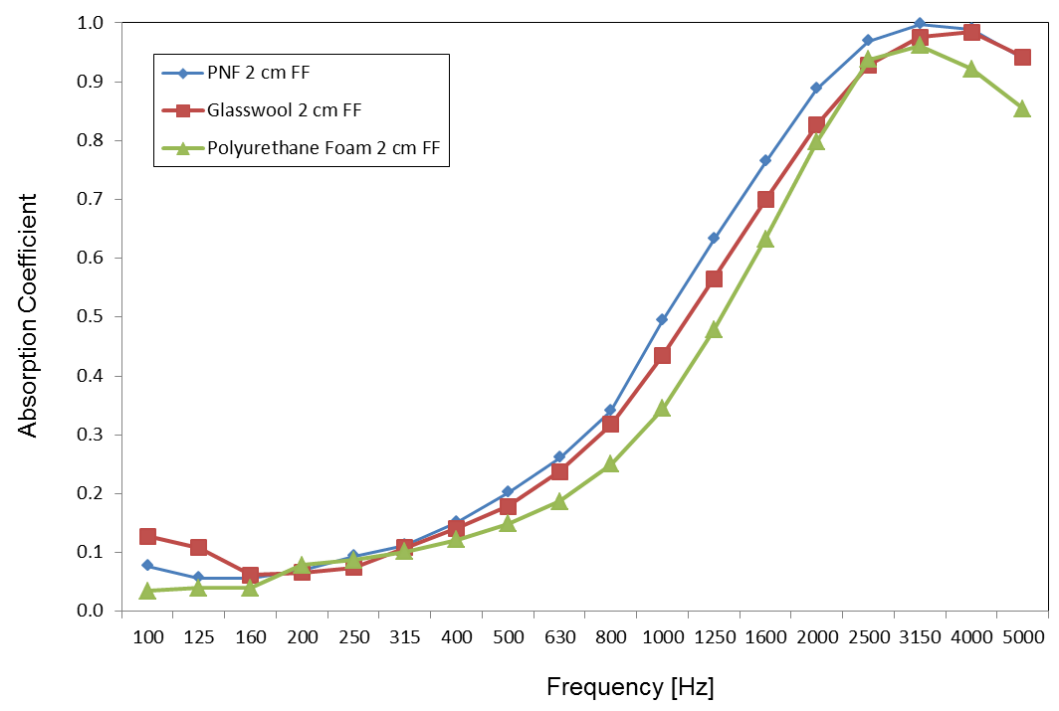

Fig. 7. Comparison between PNF absorption with other commercial acoustic absorbers.

Lastly, Fig. 7 shows a comparison between PNF absorption performances with other acoustic absorbers. With the same thickness, it can be seen that PNF absorber with front woven facing shows its dominance among others materials. The highest sound absorption performance is obtained from $500-4000 \mathrm{~Hz}$. The performance difference is even up to 0.1 at around $1300 \mathrm{~Hz}$ whereas the effective sound quality range is placed. From this information, it can be concluded that PNF fibres with front woven fabric facing is effective to be employed in any mechanical or even building applications. 


\section{Summary}

The effect of woven fabric facing and air back cavity on the sound absorption performance has been investigated experimentally. It is found that both parameters give significant effect of increasing the acoustical performance. This result can possibly expands the application of nonwoven fabric usage particularly for area that needs air cavity gap or aesthetic look of the sound absorber materials without reducing the sound quality performance for example building, environment and ventilation.

This work was financially supported by Faculty of Engineering Technology, Universiti Teknikal Malaysia Melaka (UTeM).

\section{References}

1. INDA, INDA Nonwoven Glossary, 69 (2002)

2. N.A. Kalebek, Fib. and Text. in East. Eur., 24 (1), (2016)

3. D, Gon, P. Paul, K. Das, The Ind. Text. J. 9 (2013)

4. Y. Lee, C. Joo, AUTEX Res. J. 3 (2), (2003)

5. D.V. Parikh, Y. Chen, L. Sun, Text. Res. J. 76 (11), (2006)

6. M. Tascan, E.A. Vaughn, Text. Res. J. 78 (4), (2008)

7. M. Kucuk, Y. Korkmaz, Text. Res. J. 82 (20), (2012)

8. J. Liu, W. Bao, L. Shi, B. Zuo, W. Gao, Appl. Acoust. 76 (2014)

9. A. Tiuc, H. Vermesan, T. Gabor, O. Vasile, En. Proc. 85 (2016)

10. T. Shimizu, S. Koizumi, Build. Env. 94 (2015)

11. K. Ghorbani, H. Hasani, M. Zarrebini, R. Saghafi, Alex. Eng. J. 8 (2015) 